\begin{tabular}{|c|c|c|}
\hline & Int.J.Curr.Microbiol.App.Sci (2021) 10(09): $431-440$ & \\
\hline EXCELLENT & $\begin{array}{l}\text { International Journal of Current Microbiology and Applied Sciences } \\
\text { ISSN: 2319-7706 Volume } 10 \text { Number } 09 \text { (2021) } \\
\text { Journal homepage: } \underline{\text { http://www.ijcmas.com }}\end{array}$ & $\$ Q^{\circ} \otimes$ \\
\hline $\begin{array}{l}\text { EXCELLENT } \\
\text { PUBLISHERS }\end{array}$ & & \\
\hline
\end{tabular}

Original Research Article

https://doi.org/10.20546/ijcmas.2021.1009.050

\title{
Norovirus and Adenovirus Among Children from Public Day Care Centers in Brazil
}

\author{
E. A. M. Rodrigues, D. M. Teixeira, R. S. Bandeira, J. A. M. Siqueira, \\ E. C. S. Júnior, M. S. S. Lucena, L. S. Soares, Y. B. Gabbay and L. D. Silva*
}

Instituto Evandro Chagas/Health Surveillance Secretariat/ Brazilian Ministry of Health, Highway BR 316 km 07 - Ananindeua, Para, Brazil

*Corresponding author

\section{A B S T R A C T}

Keywords

Gastroenteritis,

Norovirus,

Adenovirus,

Daycare Center,

Brazil

Article Info

Accepted:

15 August 2021

Available Online:

10 September 2021
Introduction: Enteric viruses, including noroviruses and adenovirus are pathogens associated with outbreaks and sporadic cases of gastroenteritis in worldwide. This study aimed investigate cases of gastroenteritis caused by noroviruses and adenoviruses in children attending Public Daycare Centers in Brazil. Material and Methods: In this study, 135 fecal samples were examined using RT-PCR assays, sequencing and phylogenetic analysis. Results: The prevalence for norovirus and adenovirus was $13.3 \%(18 / 135)$ and $58.5 \%$ (79/135), respectively. Noroviruses were more frequent in symptomatic individuals $(22.7 \%)$, whereas adenoviruses were more observed in asymptomatic children (61.8\%). Three norovirus genotypes were detected (GII.P4, GII.P7, GII.P12) and adenovirus strains were classified into five species (A-F). The data revealed the dynamics of genotypic distribution of noroviruses and adenoviruses among children attending day care centers. The data indicated that symptomatic and asymptomatic children were infected with several strains of NoV e AdV. The additional evolutionary analyses need to be further investigated.

\section{Introduction}

Acute gastroenteritis (AG) is important causes of morbidity and mortality worldwide, producing more than one million hospitalizations per year, especially among children up to five years of age in developing countries (Patel et al., 2008; Sebert, 2008;).
Norovirus (NoV) are positive single-stranded RNA viruses belong to Caliciviridae family, classified into ten genogroups (GI to GX), with approximately 49 genotypes described, including human strains (GI, GII and GIV genogroups) (Chhabra et al., 2019). Adenovirus (AdV) are non-enveloped, doublestranded DNA viruses, member of 
Adenoviridae family and related to respiratory, gastrointestinal and conjunctival diseases. There are $67 \mathrm{AdV}$ serotypes described and classified into seven viral species (A-G) (Ison et al., 2016).

Enteric viruses are related to outbreaks that occur in daycare centers, hospitals and cruise ships (Patel et al., 2008). The high spread of enteric viruses in these closed environments, is due to several factors, including the low viral doses necessary to initiate an infectious process, linked to the fecal-oral route as transmission. In addition, the virus particles could spread through objects that facilitate the process of infection and contamination when handled, as well as aerosols and contaminated food and water (Borges et al., 2006; Koh et al., 2011; Atmar et al., 2010).

Thus, the child population attending day care centers could be vulnerable to the spread of infectious agents (Akihara et al., 2005; Ferreira et al., 2012). Considering the limited data in our region, this study aimed investigate cases of gastroenteritis caused by noroviruses and adenoviruses in children attending public Day Care Centers.

\section{Materials and Methods}

\section{Study design and sample collection}

This was a cross-sectional and prospective study conducted at two Day Care Centers (DC I and DC II) in Ananindeua, Pará state, northern Brazil. These institutions provide services to approximately 400 children from six months to ten years of age, full-time or part-time. During the study, a multidisciplinary team made two weekly visits to the institutions. These visits included: socio-educational lectures; clinical and epidemiological assessments of patients; collection of fecal samples from patients with gastroenteritis.
From August 2014 to June 2016, fecal samples were collected from children with and without symptoms of gastroenteritis, with parental consent and after clinical analysis and application of an epidemiological questionnaire. The gastroenteritis cases were defined as presence of diarrhea with three or more liquid or pasty bowel movements in the 24 hours prior to collection. In addition to symptomatic patients were also added children asymptomatic, who did not presented gastroenteritis in the 72 hours prior to collection.

\section{Ethical considerations}

This study was approved by Research Ethics Committee of Evandro Chagas Institute under process number 449.025 .

\section{Sample's processing and nucleic acid extraction}

From the collected samples were prepared fecal suspensions in $10 \%(\mathrm{w} / \mathrm{v})$ in Tris $\mathrm{HCl}$ $\mathrm{Ca}^{++} 0.01 \mathrm{M}, \mathrm{pH}$ 7.2. The nucleic acid extraction was performed with $300 \mu \mathrm{L}$ of fecal suspensions by isothiocyanate guanidine/silica method (Boom et al., 1990). Additionally, samples for sequencing were extracted using a commercial kit (QIAamp Viral RNA Mini kit, Qiagen), following the manufacturer's instructions.

\section{Norovirus and adenovirus detection}

NoV screening in fecal specimens was carried out using the commercial Ridascreen Norovirus $3^{\text {rd }}$ Generation (R-Biopharm) EIA kit, which detects viral antigens from the GI and GII genogroups, according to manufacturer's guidelines. For AdV, due to the absence of a enzyme immunoassay, detection was performed by nested PCR using the primers Hex1Deg and Hex2Deg in the first step, followed by the NeHex3Deg and 
NeHex4Deg primers in the second step (Allard et al., 2001).

\section{Molecular characterization}

The NoV and AdV molecular characterization was performed by direct sequencing of amplicons (Fankhauser et al., 2002).

For norovirus, positive samples in EIA, were subjected cDNA synthesis by reverse transcription (RT) using a $[\mathrm{pd}(\mathrm{N}) 6]$ random primer with the SuperScript II Reverse Transcriptase (Invitrogen).

Then it was performed semi-nested PCR for ORF1-2 junction, using the primers Mon 431/G2SKR and COG2F/G2SKR, which produce amplicons of 557 and $390 \mathrm{bp}$. The samples were also screened for the GI using a semi-nested PCR with primers Mon432/G1SKR (first round) and COG1F/ G1SKR (second round) generating an amplicon of $\sim 543 \mathrm{bp}$ and $376 \mathrm{bp}$, respectively (Fankhauser et al., 2002; Vennema et al., 2002).

For AdV detection was carried out nestedPCR using the primers S29 and S52 that are targeted for three hypervariable regions (HVRs) of the hexon gene Li et al., 2004. The primers gave an amplicon of $668 \mathrm{pb}$ and PCR was performed according to Dey et al., 2011.

It was used UltraPure DNase/RNase-Free Distilled Water (Invitrogen, USA) as negative control in all reactions performed and the reagent mixture and reactions were conducted in separate rooms to avoid crosscontamination.

The positive samples were purified using the PureLink PCR Purification Kit (Invitrogen) according to the manufacturer's protocol. The amplicons were sequenced with the same primers used in the PCR assays with the support of the Big Dye Terminator Cycle Sequencing Ready Reaction Kit in the ABI Prism 3130XL DNA Sequencer (Applied Biosystems, USA) platform.

All reactions were performed using ultraPure DNase/RNase-free distilled water (Invitrogen, USA) as negative control and the reagent mixture and reactions were conducted in separate rooms to avoid cross-contamination.

\section{Phylogenetic analysis}

Preliminary analyses of the NoV genotypes were performed in Norovirus Genotyping Tool Version 1.0 (http://www.rivm.nl/ norovirus/typingtool) (Kroneman et al., 2011). Nucleotide similarity with other $\mathrm{NoV}$ and AdV sequences available in the GenBank database was verified using the Basic Local Alignment Search Tool (BLAST). Sequence alignment was performed with reference strains using the AliView program (Larsson 2014).

The selection of the substitution model and the construction of the phylogenetic dendrograms were done by IQtree software (Nguyen et al., 2015), using maximum likelihood inference and ultrafast bootstrap mode with 1000 replicates.

The substitution models used were: $\mathrm{K} 2 \mathrm{P}+\mathrm{G} 4$ (junction and capsid region-paired samples dendrograms) and HKY + G4 (dendrogram of the $\mathrm{C}$ region of the capsid-fecal samples). The editing of the dendrograms was done through the program Fig Tree v.1.4.3 (Rambaut 2019).

\section{Statistical analyses}

Statistical analyzes were performed in the program BioEstat 5.0 (Ayres et al., 2007). The nonparametric $\mathrm{G}$ and chi-square test was applied, p-values $\leq 0.05$ were considered statistically significant. 


\section{Results and Discussion}

During the study period, a reduced frequency of symptomatic cases was observed, so to expand the scope of the research, the collection of samples in asymptomatic cases was expanded to verify viral circulation among asymptomatic children. From August 2014 to June 2016 were collected and analyzed 135 fecal samples of children attending in the participating daycares (DC I and DC II).

Noroviruses e adenoviruses were detected in $65.2 \%(88 / 135)$ of the collected samples. NoV was identified in $13.3 \%(18 / 135)$ and AdV in $57.8 \%(78 / 135)$ of the samples. Cases of coinfection (norovirus and adenovirus) were observed in $6.7 \%(9 / 135)$ of the analyzed samples. In four samples it was not possible identify the place of collection due to lack of information on the epidemiological form, however one of them was positive for $\mathrm{NoV}$ $(25 \%, 1 / 4)$ and two for $\operatorname{AdV}(50 \%, 2 / 4)$ (Table 1).

The study involved the investigation of 22 fecal samples from children who had symptoms of gastroenteritis and 111 samples from children who did not have gastroenteritis. The distribution according to the presence of gastroenteritis showed that: NoV were observed in $22.7 \%(5 / 22)$ and $11.7 \% \quad(13 / 111) \quad$ of symptomatic and asymptomatic cases, respectively; AdV were more verified in asymptomatic $(61.3 \%$ $68 / 111)$ than in symptomatic cases $(45.5 \%$ $10 / 22)\left(\mathrm{p}^{2}=1.296 ; \mathrm{p}<0.2550\right)$; in two samples in which individual's health condition was not reported in the form, one of them showed the AdV presence (Table 1).

NoV affected more young children up to two years of age (21.4\% [6/28]), while AdV infection occurred more in children of three to five years of age (69\%-29/42) (Table 2). The temporal distribution showed a high frequency of $\mathrm{AdV}$ in relation to the $\mathrm{NoV}$ with rates of $100 \%$ in October 2014/November 2015 and 82\% in April 2016 (Figure 1).

Based on the partial sequence of the polymerase region, the norovirus sequences were classified in three different genotypes: GII.P4, GII.P7 and GII.P12 (Figure 2). The amplification of the conserved region of the $\mathrm{AdV}$ Hexon gene was performed in 33 (41.8\%) of the $79 \mathrm{AdV}$ positive samples, with the partial characterization of five genotypes: AdV-A $(n=1 \ldots 3.0 \%)$, AdV-B $(n=3$ _ $9.1 \%)$, AdV C ( $\mathrm{n}=19$ _ 57.6\%), AdV-D ( $\left.\mathrm{n}=1 \_3.0 \%\right)$ and AdV-F ( $\mathrm{n}=9$ - 27.3\%). These samples were analyzed in hypervariable regions, with evidence of two distinct clusters for AdV-2 (AdV-2a, AdV-2b). Besides, two samples showed distinct patterns with evidence of homology with a feline strain and possible intergenotypic recombination (Figure 3).

Despite the role of these viruses in an asymptomatic infection remains unclear, in this investigation we demonstrate that enteric viruses-related to outbreaks have importance in children without gastroenteritis (Van et al., 1992; Gallimore et al., 2004; Hartman et al., 2019). Considering the genetic diversity of norovirus and adenovirus, continuous surveillance of symptomatic and asymptomatic cases, for monitoring genotypes and the emergence of new strains is required (Jensen et al., 2019).

This study demonstrated the frequency and genotypic characterization of norovirus and adenovirus strains circulating among children attending daycare centers in Belem, a city located in the northern region of Brazil, a geographical region where the prevalence of AG is high. Other studies suggest that NoV and HAdV can be detected in approximately $25 \%$ and $5 \%$ of stool samples collected from children without diarrhea (Okitsu et al., 2020). 
Figure.1 Monthly distribution and detection rates of norovirus and adenovirus in faecal samples from symptomatic and asymptomatic children from two day care centers located in Ananindeua, Brazil.

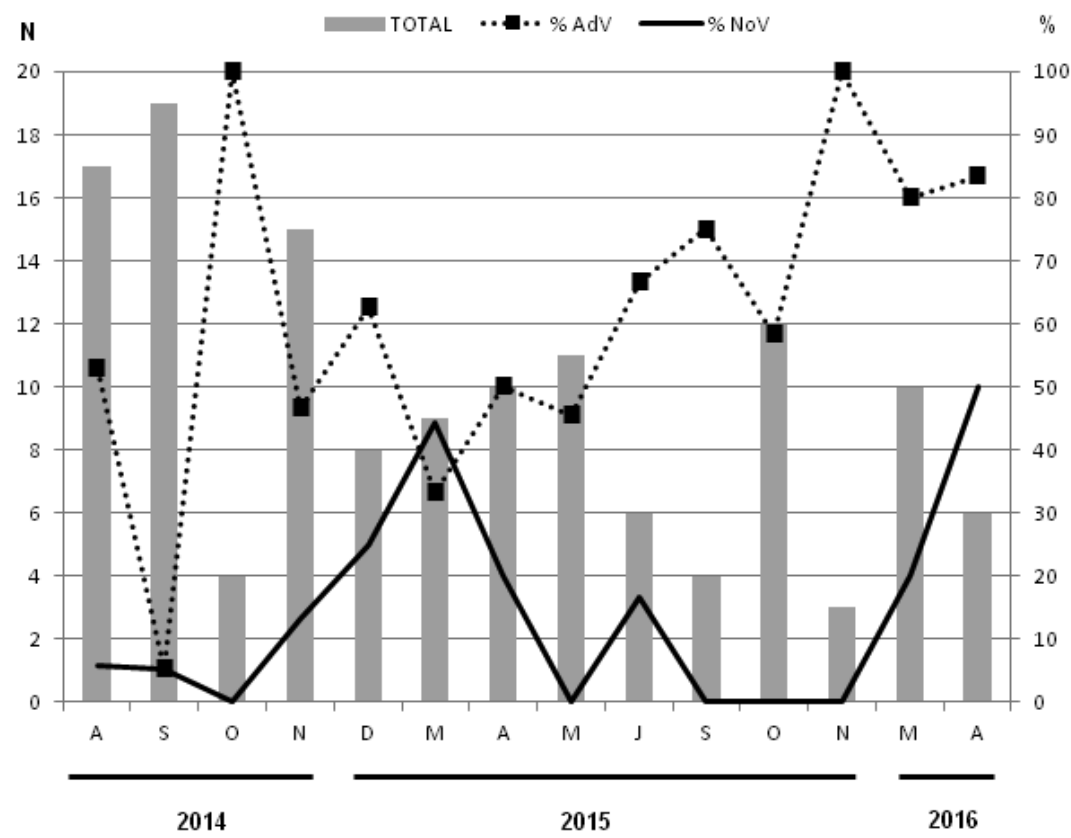

Figure.2 Phylogenetic tree based on a partial RdRp region of norovirus GII identified from fecal samples from children in two day care centers located in Ananindeua, Brazil. Study samples are marked with bold and filled circles. The scale bar is proportional to the genetic distance.

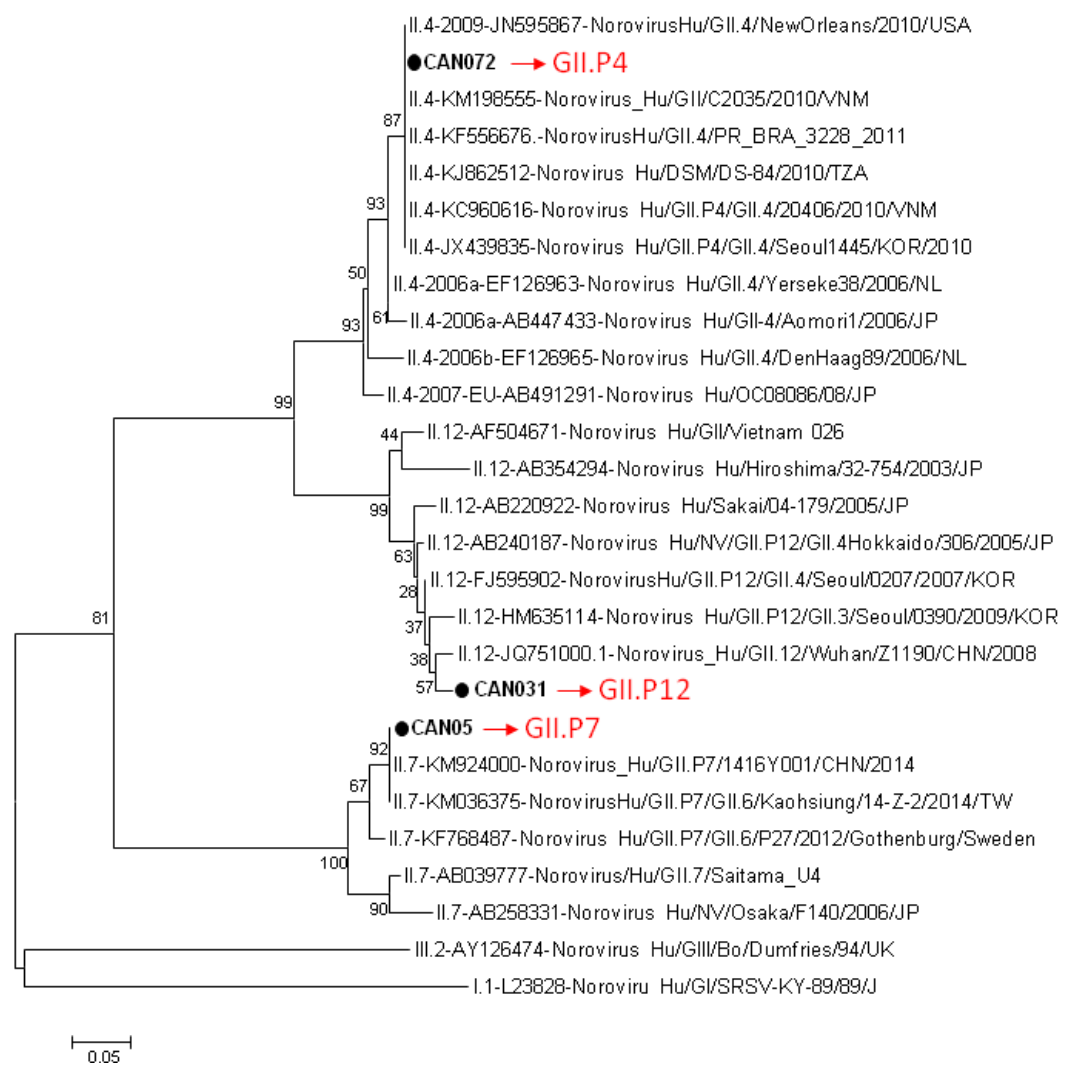


Figure.3 a) Phylogenetic tree of adenovirus genotypes identified from fecal samples from children in twoday care centers located in Ananindeua, Brazil. Study samples are marked with bold and filled circles. The scale bar is proportional to the genetic distance.

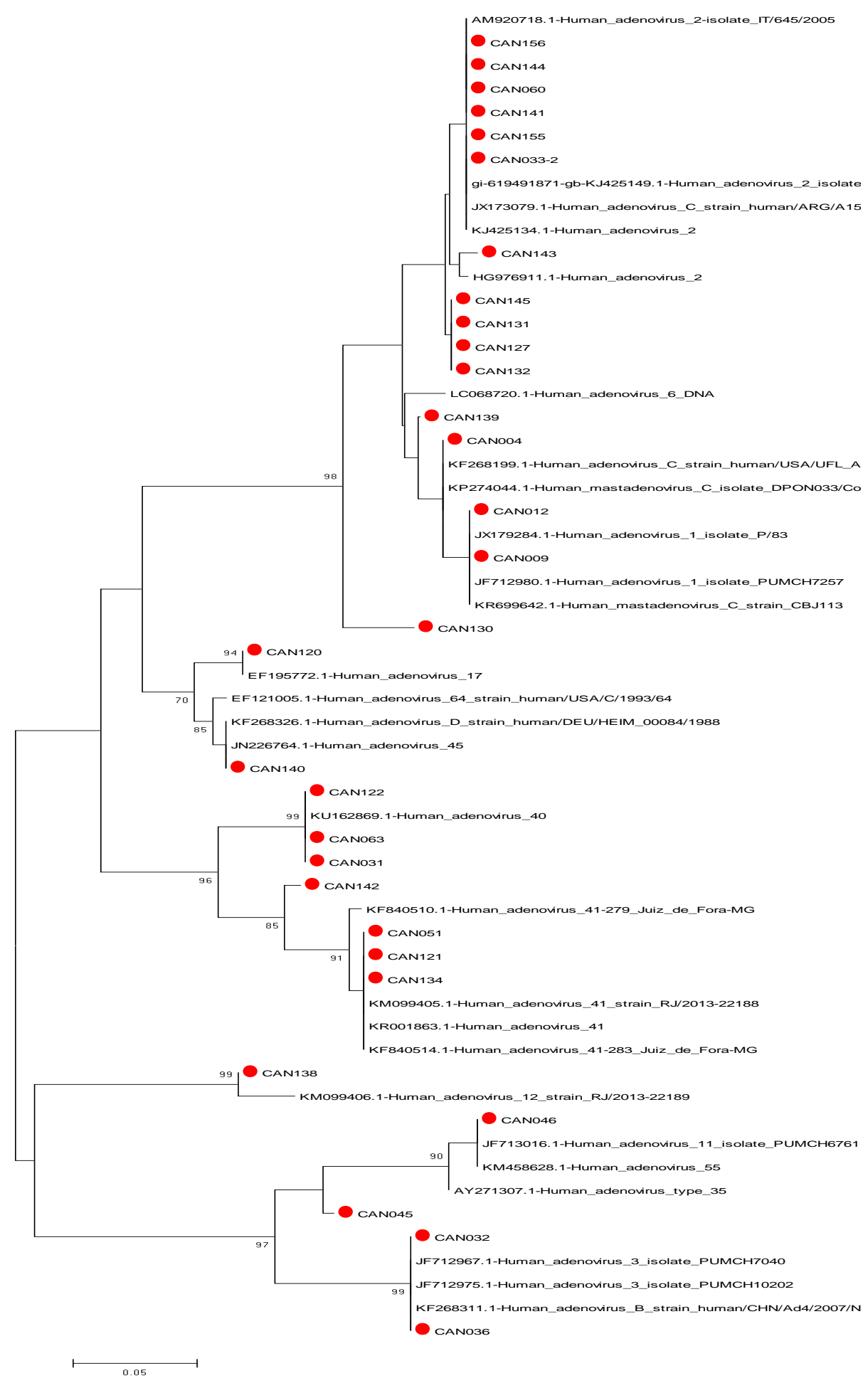


Figure.3 b) Phylogenetic tree based on a partial Hexon gene of adenovirus identified from fecal samples from children in two day care centers located in Ananindeua, Brazil. Study samples are marked with bold and filled circles. The scale bar is proportional to the genetic distance.

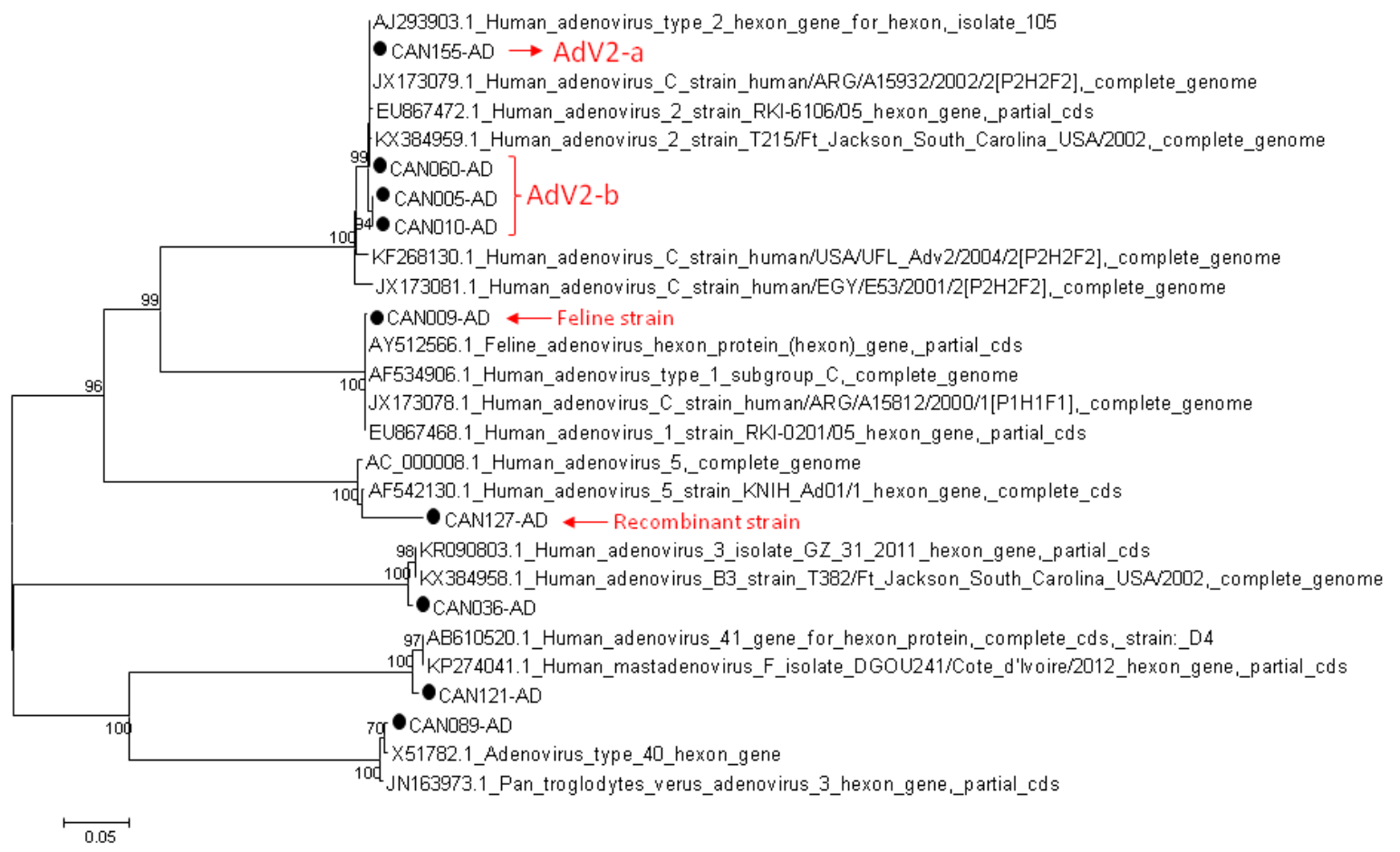

The viral excretion by asymptomatic individuals proposes that children could act as a reservoir that constitute source of viral dissemination to the community (Gallimore et al., 2004). This information is corroborated in several studies and adds an important hypothesis for future studies, which is related to the evolutionary studies of emerging viral strains that may present a risk of outbreaks to human populations, since they are already in circulation accompanied by potentially pathogenic viruses (Bucardo et al., 2010; Lynch et al., 2011; Lion et al., 2014; Okitsu et al., 2020).

Our results also showed that HAdV affected older children (3-5 years old) while NoV caused infection in children up to two years old (up to two years old). In general, more than $80 \%$ of HAdV infections occur in children $<4$ years of age due to lack of humoral immunity (Lynch et al., 2011). In asymptomatic Nicaraguan children the NoV were observed in $11.7 \%$ of the stool samples mainly in $\leq 6$ months of age children and this rate was very similar to that found in the present study (13.3\%) (Bucardo et al., 2010). In fact NoV tends to affect younger children and this shows that they are exposed to the virus at an early age, especially in developing countries (Altan et al., 2018).

In this research we detected the genotypes GII.P4, GII.P7 and GII.P12, all of these are described as cause of AG outbreaks by NoV, having been initially detected in Brazilian daycare centers associated with outbreaks of gastroenteritis in 1996 (Gallimore et al., 2004). GII.P7 and GII.P12 genotypes are considered unusual NoV types that can associated with asymptomatic infections (Bucardo et al., 2010).

Most of the AdV strains identified belonged to species $C(n=19)$ and species $F(n=9)$. Samples characterized as AdV-C, known to cause 
ocular manifestations and respiratory tract infections, were verified mainly $(94.7 \%)$ in the feces of asymptomatic children.

As already described, AdV replicates in the gastrointestinal tract of infected individuals and are excreted in the faeces, regardless of their clinical manifestations, and this includes AdV-C. However, AdV-F (types 40 and 41) are endemic and are closely involved in symptomatic cases of AG and diarrheal disease in children (Lynch et al., 2011; Lion et al., 2014).

The detection of viral agents (including HAdV and NoV) in children without any symptoms of AG is well documented (Lynch et al., 2011; Okitsu et al., 2020). Studies conducted with metagenomics analysis reported the human enteric virome, which can present several viruses of the Picornaviridae and Caliciviridae families (Altan et al., 2018, Siqueira et al., 2018). The presence these viruses in asymptomatic may facilitate the environmental contamination and transmission to susceptible individuals, mainly in places with precarious sanitation and hygienic conditions (Okoh et al., 2010).

Other considerations related to the findings of this study refer to the presence of recombinant strains of HAdV. Novel strains always arise from mutations or intratypic recombination among different types of HAdV (Wang et al., 2016).

Therefore, the evidence detected in this study suggests events that may increase the genetic diversity of AdV strains, which may constitute an escape mechanism for the host's immune system (La Rosa et al., 2015; Wang et al., 2016). Despite the findings, further studies are needed in order to elucidate important aspects of viral antigenic diversity and genomic composition, due to the importance of these agents as causing enteric infections.

\section{References}

Akihara S, Phan T G, Nguyen T A, Hansman G, Okitsu S, Ushijima H. Existence of multiple outbreaks of viral gastroenteritis among infants in a day care center in Japan. Arch Virol. 2005:150:2061-75.

Allard A, Albinsson B, Wadell G. Rapid typing of human adenoviruses by a general PCR combined with restriction endonuclease analysis. J Clin Microbiol. 2001: 39(2):498-505.

Altan E, Aiemjoy K, Phan T G, Deng X, Aragie S, Tadesse Z, Callahan K E, Keenan J, Delwart E. Enteric virome of Ethiopian children participating in a clean water intervention trial. PLoS One. 2018 Aug 16;13(8):e0202054.

Atmar R L. Noroviruses - State of the art. Food Environ Virol. 2010:2:117-26.

Ayres M, Ayres Jr M, Ayres D L, dos Santos AS. BioEstat 5.0: Aplicações estatísticas nas áreas das ciências biológicas e médicas. 5ed. Belém, Instituto de Desenvolvimento Sustentável Mamirauá - IDSM/MCT /CNPq. 2007. 364pp.

Boom R, Sol C J A, Salimans M M M, Jansen, C L, Wertheim-Van Dillen PME, Noordaa-Van Der J. Rapid and simple method for purification of nucleic acids. J Clin Microbiol. 1990:28:495-503.

Borges A M, Teixeira J M, Costa PS, Giugliano L G, Fiaccadori F S, Franco R D E C, Brito W M, Leite J P, Cardoso D D. Detection of calicivirus from fecal samples from children with acute gastroenteritis in the West Central region of Brazil. Mem Inst Oswaldo Cruz. 2006:101:721-4.

Bucardo F, Nordgren J, Carlsson B, Kindberg E, Paniagua M, Möllby R, \& Svensson L. Asymptomatic Norovirus infections in nicaraguan children and its association with viral properties and histo-blood group antigens. Ped Infect 
Dis J. 2010:29:934-9.

Chhabra P, de Graaf M, Parra G I, Chan M C, Green K, Martella V, Wang Q, White P A, Katayama K, Vennema H, Koopmans M P G, Vinjé J. Updated classification of norovirus genogroups and genotypes. J Gen Virol. 2019:100:1393-6.

Dey $\mathrm{R}$ S, Ghosh S, Chawla-Sarkar M, Panchalingam S, Nataro J P, Sur D, Manna B, Ramamurthy T. Circulation of a novel pattern of infections by enteric adenovirus serotype 41 among children below 5 years of age in Kolkata, India. $\mathbf{J}$ Clin Microbiol. 2011:49:500-5.

Fankhauser R L, Monroe S S, Noel J S, Humphrey C D, Bresee JS, PARASHAR, U.D. Epidemiological and molecular trends of "Norwalk-like viruses" associated with outbreaks of gastroenteritis in the United States. The Journal of Infectious Diseases. v. 186, n. 1, p.1-7, 2002.

Ferreira M S R, Xavier M D P T P, Tinga A C D C, Rose T L, Fumian T M, et al., Assessment of gastroenteric viruses frequency in a children's day care center in Rio De Janeiro, Brazil: a fifteen year study (1994-2008). PLoS ONE. 2012:7: e33754.

Gallimore C I, Barreiros M A B, Brown D W G, Nascimento J P, Leite J P G. Noroviruses associated with acute gastroenteritis in a children's Day care facility in Rio de Janeiro, Brazil. Braz J Med Biol Res. 2004:37:321-6.

Hartman S, Brown E, Loomis E, Russel H A. Gastroenteritis in children. Am Fam Physician. 2019:99:159-65.

Ison $\mathrm{M} \mathrm{G}$, Hayden $\mathrm{R} \mathrm{T}$. Adenovirus. Microbiol Spectr. 2016:4:1-14.

Jensen B H, Jokelainen P, Nielsen A C Y, Franck K T, Holm D R, Schonning K, Petersen A, Frogfelt K A. Children attending day care centers are a yearround reservoir of gastrointestinal viruses. Sci Rep. 2019:9:1-8.
Koh S, Cho, H G, Kim B H, Choi B Y. An outbreak of gastroenteritis caused by norovirus contaminated ground water at a water park in Korea. J Korean Med Sci. 2011:26:28-32.

Kroneman, A., Vennema, H., Deforche, K., Avoort. H. V., Peñaranda, S., Oberste, M. S., Vinjé, J., Koopmans, 2011. An automated genotyping tool for enteroviruses and noroviruses. J. Clin. Virol., 51, 121-125.

La Rosa G, Della Libera S, Petricca S, Iaconelli M, Donia D, Saccucci P, Cenko F, Xhelilaj G, Divizia M. Genetic Diversity of Human Adenovirus in Children with Acute Gastroenteritis, Albania, 2013-2015. Biomed Res Int. 2015. 2015:142912.

Larsson A. AliView: a fast and lightweight alignment viewer and editor for large datasets. Bioinformatics. 2014;30(22):3276-8.

Li L, Shimizu H, Doan L T P, Tung P G, Okitsu S, Nishio O, Suzuki E, Seo J K, Kim K S, Muller W E G, Ushijima H. Characterization of adenovirus type 41 isolates from children with acute gastroenteritis in Japan, Vietnam, and Korea. J Clin Microbiol. 2004:42:40329.

Lion T. Adenovirus infections in immunocompetent and immunocompromised patients. Clin Microbiol Rev. 2014:27:441-62.

Lynch J P, Fishbein M, Echavarria M. Adenovirus. Semin Respir Crit Care Med. 2011:32:494-511.

Nguyen L T, Schmidt H A, von Haeseler A, Minh BQ. IQ-TREE: a fast and effective stochastic algorithm for estimating maximum-likelihood phylogenies. Mol Biol Evol. 2015;32(1):268-74.

Okitsu S, Khamrin P, Takanashi S, Thongprachum A, Hoque S A, Takeuchi H, Khan M A, Hasan S M T, Iwata T, Shimizu H, Jimba M, Hayakawa S, 
Maneekarn N, Ushijima H. Molecular detection of enteric viruses in the stool samples of children without diarrhea in Bangladesh. Infect Genet Evol. 2020:77:104055.

Okoh A I, Sibanda T, Gusha S S. Inadequately treated wastewater as a source of human enteric viruses in the environment. Int $\mathbf{J}$ Environ Res Public Health. 2010 Jun;7(6):2620-37.

Patel M M, Widdowson M A, Glass R I, Akazawa K, Vinje J, Parashar U D. Systematic literature review of role of noroviruses in sporadic gastroenteritis. Emerg Infect Dis. 2008:14:1224-31.

Rambaut, A. FigTree. Tree Figure Drawing Tool version 1.4.3. University of Edinburgh: Institute of Evolutionary Biology; 2009 [http://tree.bio.ed.ac.uk/].

Sebert M. Gastroenteritis. In: Bergelson J M, Shan S S, Zaoutis T E, editors. Pediatric infectious diseases: The requisites in pediatrics. Philadelphia: Elsevier: 2008. p. 157-68.
Siqueira J D, Dominguez-Bello M G, Contreras M, Lander O, Caballero-Arias H, Xutao D, Noya-Alarcon O, Delwart E. Complex virome in feces from Amerindian children in isolated Amazonian villages. Nat Commun. 2018, 15;9(1):4270.

Van R, Wun C C, O'Ryan M L, Matson D O, Jackson L, Pickering L K. Outbreaks of human enteric adenovirus types 40 and 41 in Houston day care centers. J Pediatr. 1992:120:516-21.

Vennema H, De Bruin E, Koopmans M. Rational optimization of generic primers used for Norwalk-like vírus detection by reverse transcriptase polymerase chain reaction. J Clin Virol. 2002:25:233-5.

Wang Y, Li Y, Lu R, Zhao Y, Xie Z, Shen J, Tan W. Phylogenetic evidence for intratypic recombinant events in a novel human adenovirus $\mathrm{C}$ that causes severe acute respiratory infection in children. Sci Rep. 2016; 6:23014.

\section{How to cite this article:}

Rodrigues, E. A. M., D. M. Teixeira, R. S. Bandeira, J. A. M. Siqueira, E. C. S. Júnior, M. S. S. Lucena, L. S. Soares, Y. B. Gabbay and Silva, L. D. 2021. Norovirus and Adenovirus Among Children from Public Day Care Centers in Brazil. Int.J.Curr.Microbiol.App.Sci. 10(09): 431440. doi: https://doi.org/10.20546/ijcmas.2021.1009.050 